\title{
Multilocus heterozygosity at protein loci and fitness in the European oyster, Ostrea edulis L.
}

\author{
G. Alvarez, \\ C. Zapata, ${ }^{*}$ \\ R. Amaro* and \\ A. Guerrat
}

\author{
* Departamento de Biología Fundamental, Facultad \\ de Biología, Universidad de Santiago de Compostela, \\ Santiago de Compostela, Spain. \\ † Centro Experimental de Vilaxoán, Consellería de \\ Pesca. Xunta de Galicia, Spain.
}

The relationship between multilocus heterozygosity at protein loci and two fitness traits, growth rate and viability, has been investigated in the European oyster, Ostrea edulis $L$. A cohort of individuals of the same age was sampled at two times when they were 18 and 30 months old. Weight and genotype for five polymorphic enzyme loci were determined for individuals of these two samples. A positive correlation between growth rate (measured as weight at a specific age) and multilocus heterozygosity is detected in the two age classes. The correlation is statistically significant for the 30-month-old oysters, in which heterozygosity explains about 2 per cent of the variability in growth rate among individuals. This value is very similar to those reported in several marine molluscs, as the American oyster, Crassostrea virginica (Zouros et al., 1980) and the mussel Mytilus edulis (Koehn and Gaffney, 1984), and other species.

The relationship between multilocus allozyme heterozygosity and viability has usually been described in statistical terms, but the viability effects associated with heterozygosity have not been quantified. In this paper, we attempt to measure viability for individuals differing in their degree of multilocus allozyme heterozygosity by using appropriate fitness estimators. In the $O$. edulis cohort, a decrease of the postsettlement viability estimates is observed when individual heterozygosity increases, and this unexpected pattern might be related to the high mortalities observed. On the other hand, published data of $\boldsymbol{C}$. virginica and $\boldsymbol{M}$. edulis, from which a heterozygosity-viability positive correlation was reported (Zouros et al., 1983; Diehl and Koehn, 1985), are used for estimating viability fitnesses for heterozygosity classes. In all three species large differences in estimates of viability and selection coefficients appear to be associated with multilocus allozyme heterozygosity (mean postsettlement viabilities for heterozygous individuals at one or more loci are $0.51 \pm 0.12$ in $O$. edulis, $2.68 \pm 0.67$ and $2.35 \pm 0.38$ in two populations of $C$. virginica, and $2 \cdot 19 \pm 0.47$ in $M$. edulis). The extent of the fitness estimates suggests that the magnitude of the association between allozyme heterozygosity and viability is stronger than that corresponding with growth rate in the three species of marine molluscs. The implications of these findings in relation to the genetic mechanism underlying the heterozygosityfitness correlation are discussed.

\section{INTRODUCTION}

In recent years, experimental studies have demonstrated the existence of a relationship between multilocus heterozygosity at electrophoretically detectable enzyme loci and fitness traits in many natural populations. This phenomenon is not universal, but is frequently found in outbreeding species for traits as developmental stability, survival and, especially, growth rate (see Mitton and Grant, 1984, and Zouros and Foltz, 1987, for reviews).

Positive associations between allozyme heterozygosity and fitness-related characters have been observed in a variety of marine molluscs including the American oyster, Crassostrea virginica (Singh and Zouros, 1978, 1981; Zouros et al., 1980, 1983), the Pacific oyster, Crassostrea gigas (Fujio, 1982), the mussel Mytilus edulis (Koehn and Gaffney, 1984; Diehl and Koehn, 1985; Rodhouse et al., 1986), the clams Mulinia lateralis (Garton et al., 1984; Koehn et al., 1988) and Macoma balthica (Green et al., 1983), and the scallop Placopecten magellanicus (Foltz and Zouros, 1984). The present paper is an attempt to relate multilocus heterozygosity at allozyme loci with fitness in the European or flat oyster Ostrea edulis L, a species of marine mollusc in which this relationship has not previously been investigated. The European oyster is a species living on the Atlantic coasts of Europe and the Mediterranean Sea, and with a mode of reproduction (the female broods the larvae) different from the bivalves that have been studied previously. 
Our work with $O$. edulis concerns two relevant traits related to fitness: growth rate and viability. Growth rate is the character most frequently studied in connection with allozyme heterozygosity, and previous investigations include a variety of animal and plant species (see Mitton and Grant, 1984, and Zouros and Foltz, 1987). On the other hand, the study of viability with respect to multilocus heterozygosity for protein loci has received comparatively little attention. Studies on viability are mainly concerned with bivalve species, although other organisms including fishes and plants have also been studied. Thus, allozyme heterozygosity increases with age in cohorts (groups of individuals of same age) of $C$. virginica (Zouros et al., 1983) and M. edulis (Diehl and Koehn, 1985). A positive association between heterozygosity and age has been reported for the scallop P. magellanicus (Foltz and Zouros, 1984) and the clam M. balthica (Green et al., 1983), two bivalve species in which the age of individuals can be directly determined by counting annual growth rings. Allozyme heterozygosity correlates with age in the marine fish Fundulus heteroclitus (Mitton and Koehn, 1975) and in the plaice Pleuronectes platessa (Beardmore and Ward, 1977). In plants, a correlation between heterozygosity for protein polymorphisms and age has been found in a study of Liatris cylindracea (Schaal and Levin, 1976). On the other hand, no evidence for a heterozygosityviability correlation has been observed in Drosophila melanogaster (Mukai et al., 1974).

It is well-known that heterozygosity for a small number of allozyme loci explains about 4 per cent of the variation in growth rate among individuals of various species (Zouros et al., 1980; Foltz et al., 1983; Koehn and Gaffney, 1984; Bush et al., 1987). In contrast, it is worthy to underline that the strength of the association between allozyme heterozygosity and viability is to date completely unknown (see Zouros and Foltz, 1987). Most studies relating viability to allozyme heterozygosity describe this association by means of statistics that do not properly quantify viability. In the majority of cases, the phenomenon is characterized by means of a statistical correlation between heterozygosity and age (Mitton and Koehn, 1975; Schaal and Levin, 1976; Beardmore and Ward, 1977; Green et al., 1983; Foltz and Zouros, 1984), or by comparing the frequency distributions of heterozygosity classes in cohorts of different age (Diehl and Koehn, 1985). In some case, viability has been quantified (Zouros et al., 1983) but the indices used do not measure viability as probability of survival of genotypes.
It is clear that the association between viability and allozyme heterozygosity must be quantified by measuring viability in terms of adaptive or fitness values. It follows that an estimation of viability fitnesses for individuals differing in their degree of multilocus heterozygosity must be carried out. This approach is attempted in this paper for $O$. edulis, along with reanalysis of published data on two other marine molluscs, the American oyster, $C$. virginica, and the mussel $M$. edulis. Large differences in estimates of viability and selection coefficients among allozyme heterozygosity classes are discovered in the three species. Moreover, the magnitude of the association of allozyme heterozygosity with viability appears to be higher than that found for growth rate. These results are relevant to the genetic mechanism underlying the heterozygosity-fitness correlation.

\section{MATERIALS AND METHODS}

To investigate the relationship between multilocus heterozygosity at electrophoretic loci and growth rate and viability in the species Ostrea edulis L., a cohort of individuals of the same age was produced. This consisted of about 15,000 individuals which were the offspring of 60 parents coming from a population located at the Ria de Ortigueira (NW Spain). In June, 1983, these parental oysters were used to produce larvae by means of the standard hatchery techniques of "mass spawnings". The larvae were obtained during a period of seven days, and were reared to spat (settling larvae) in laboratory tanks under hatchery conditions. The oysters were provided with a continuous flow of filtered sea water and fed with cultured phytoplankton. In February, 1984, spats were transferred to plastic floating trays placed in an intertidal farming bed at the Ria de Ortigueira, and were allowed to grow under outdoor farming conditions.

\section{Sampling the cohort and electropheretic analysis}

Two random samples of more than four hundred individuals were taken from the cohort when oysters were approximately 18 and 30 months old. Individuals from both of these samples were cleaned, dried of excess water and weighed. The age-specific weight is used in this study as a measure of the individual growth rate. Then, individuals were sacrificed and the soft tissue was 
removed and placed in vials, which were quickly frozen at $-40^{\circ} \mathrm{C}$, where they stayed until used for electrophoresis. For each individual, the genotype at five polymorphic allozyme loci was determined by horizontal starch-gel electrophoresis, as described by Saavedra et al., (1987). The five enzymes are: Esterase (EST, EC 3.1.1.1.), isocitrate dehydrogenase (IDH, EC 1.1.1.42), malate dehydrogenase (MDH, EC 1.1.1.37), phosphoglucose isomerase (PGI, EC 5.3.1.9.) and phosphoglucomutase (PGM, EC 2.7.5.1.). The nomenclature for the electromorphs of the loci coding the enzymes is according to Saavedra et al. (1987).

\section{Statistical methods}

Genetic variability at single loci is measured as the expected heterozygosity, or gene diversity, defined as $h=1-\sum x_{i}^{2}$ where $x_{i}$ denotes the frequency of the $i$ th allele (Nei, 1975). For a single locus, an unbiased estimate of gene diversity is given by $h=2 n\left(1-\sum x_{i}^{2}\right) /(2 n-1) \quad(\mathrm{Nei}, 1978)$, which is used in this paper. The genetic variability of the population is measured by the average heterozygosity per locus. Departures from Hardy-Weinberg proportions can be measured by means of several statistics (Li and Horvitz, 1953). We have used an $f$ statistic that has been recently developed by Robertson and Hill (1984), which measures Hardy-Weinberg deviations in terms of homozygote excess and has several interesting statistical and genetic properties. In large samples, the variance of the estimate of $f$ is $1 /(N(k-1))$, where $N$ is the sample size and $k$ the number of alleles. This estimate of $f$ can be computed for different alleles at the same locus and, in addition, has a test of significance for $f=0$ that posses a higher statistical power than the usual chi-square test (Robertson and Hill, 1984).

Estimation of relative viability of genotypes is usually done by means of the cross-product ratio estimator (Cook, 1971; Anxolabéhère et al., 1982; Alvarez et al., 1984; Connolly and Gliddon, 1984). This type of estimator measures viability selection in a proper way since it does not produce fitness estimates that present spurious frequency-dependent patterns (Alvarez et al., 1984). The measurement of viability fitness requires taking two samples of the population at consecutive stages of the life cycle (1 and 2). Thus, if $n 1_{i}$ and $n 2_{i}$ are the numbers of individuals of the $i$ th genotype in samples 1 and 2 , respectively, and $n 1_{j}$ and $n 2_{j}$ are the numbers of the $j$ th genotype in samples 1 and 2 , the estimate of viability of the $i$ genotype relative to the $j$ genotype is

$$
\hat{W}_{i}=\left(n_{2 i} / n_{2 j}\right)\left(n_{1 j} / n_{1 i}\right) .
$$

This is a general expression for the estimation of the relative viability valid for multiallelic loci, and also for multilocus genotypes. Moreover, in the above expression $i$ and $j$ can be also genotypic classes composed of several different genotypes. For example, $i$ and $j$ can be heterozygosity classes constituted by genotypes differing in the number of heterozygous loci per individual. The only problem with this estimator of relative viability is the occurrence of a statistical bias, especially for low gene frequencies (Anxolabéhère et al., 1982; Connolly and Gliddon, 1984), but this bias is negligible in comparison with the large variances associated to these estimators (Connolly and Gliddon, 1984).

The variance of the viability estimator can be obtained assuming that the two samples are independent, as has been suggested by Connolly and Gliddon (1984). In this case, the problem reduces to an evaluation of the variances of the ratios of terms of a multinomial distribution. The explicit expression for the asymptotic sampling variance of a cross-product ratio estimate has not been given by Connolly and Gliddon (1984), but, in large samples, it can be easily obtained by using "delta methods" (Elandt-Johnson, 1971). This expression is as follows:

$$
\begin{aligned}
\hat{V}\left(W_{i}\right)= & \frac{\hat{W}_{i}}{n_{1 i} n_{2 j}}\left[\frac{\left(n_{1 i}+n_{1 j}\right)\left(n_{2 i}+n_{2 j}\right)}{n_{1 i} n_{2 j}}\right. \\
& \left.+\frac{n_{2 i}\left(n_{1 i}+n_{1 j}\right)}{n_{1 i}}+\frac{n_{1 j}\left(n_{2 i}+n_{2 j}\right)}{n_{2 j}}\right]
\end{aligned}
$$

Standard statistical procedures used in the analysis of data follow those of Sokal and Rohlf (1981) and were performed using the SPSS and BIOM statistical packages.

\section{RESULTS}

\section{Weight distributions of the cohort}

A cohort of European flat oyster, Ostrea edulis L., located at the Ria de Ortigueira (NW Spain) was sampled twice, when oysters were 18 and 30 months old. Individual weight distributions of these two samples are shown in fig. 1. Statistically significant deviations from normality were detected in both samples by means of the KolmogorovSmirnov test $\left(D_{\max }\right.$ statistic is $0.051, P<0.01$, and $0.071, P<0.01$, for 18 and 30 -month-old oysters, respectively). The logarithmic transformation does 

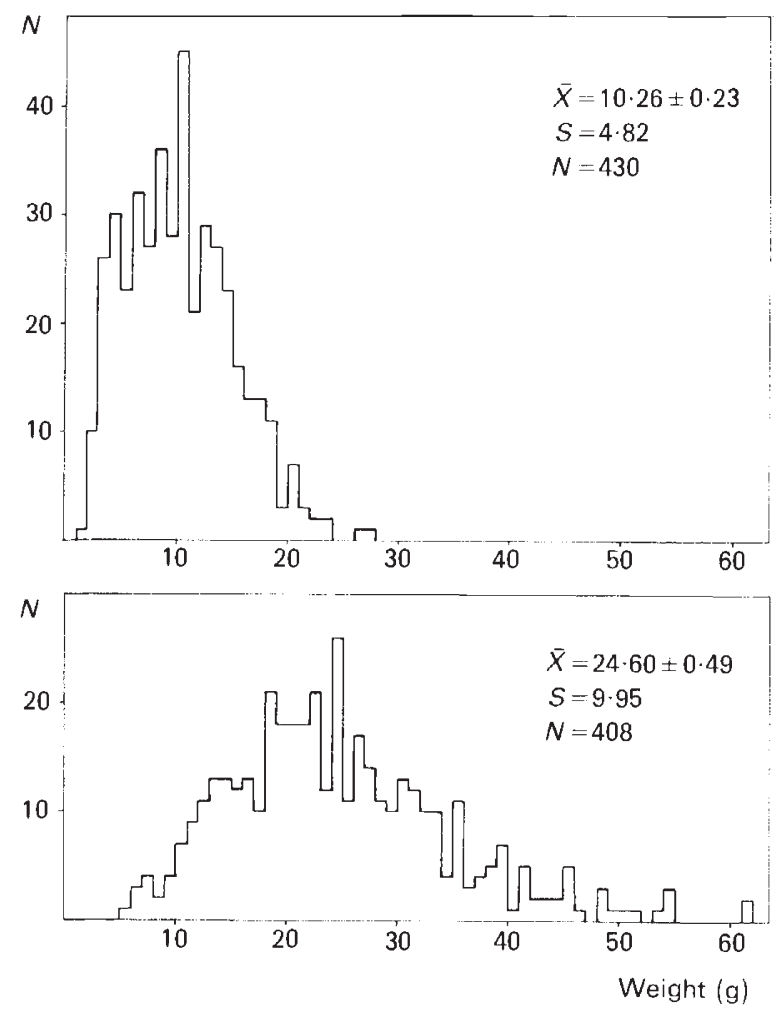

Figure 1 Individual weight distributions of two samples of a cohort of European oysters. Samples were collected when individuals were 18 (above) and 30 (below) months old. $N$ is the number of individuals.

not remove the lack of normality of the weight distributions. Departures from normal curve are mainly due to skewness to the right for 18-monthold oysters $\left(g_{1}=0.53\right.$ and $\left.g_{2}=-0.005\right)$, while deviation from normality for 30 -month-old oyster weight distribution seems to be due to both asymmetry and leptokurtosis $\left(g_{1}=0.79\right.$ and $\left.g_{2}=0.80\right)$. It is important to note that the very rapid growth of the cohort during the year between the two samples resulted in the mean weight of 30 -monthold oysters being more than twice that of the 18 month-old individuals $(24 \cdot 60 \pm 0.49$ and $10 \cdot 26 \pm$ $0 \cdot 23$, respectively).

\section{Genetic structure of the cohort}

Single-locus statistical analyses for the five polymorphic allozyme loci are shown in tables 1 and 2. The mean heterozygosities per locus were $0 \cdot 219 \pm 0 \cdot 081$ and $0 \cdot 182 \pm 0 \cdot 087$ at the 18 and 30 month-old oysters, respectively. These values are slightly less than the heterozygosity for the same loci in the natural population of oyster located at the Ria de Ortigueira. The average heterozygosity of this parental population was $0 \cdot 231 \pm 0 \cdot 087$ (data from Saavedra et al., 1987). Therefore, the cohort presents an average heterozygosity that is 79-95 per cent of the heterozygosity of the natural population and this reduction of genetic variability could be due to a "founder effect". Under neutral conditions, the outcome of a "founder effect" on the heterozygosity is given by the expression $H_{t}=$ $H_{0}(1-1 / 2 N)^{t}$, where $H_{0}$ and $H_{t}$ are the heterozygosities in the origin and in the time $t$, and $N$ is the population size (Crow and Kimura, 1970). According to this expression, a reduction of heterozygosity similar to that observed in the cohort (5-21 per cent) would correspond to an effective number of individuals between two and ten. The "founder effect" could be produced when the larvae were originated in the hatchery. The cohort was obtained from 60 parental adult oysters which produced a population of about $5 \times 10^{6}$ larvae. The fertility of $O$. edulis can vary widely (Millar, 1961; Walne, 1964; Roman, 1987), but a production of $5 \times 10^{6}$ larvae could correspond to the spawning of only $3-5$ females (6-10 parents), and these values are very close to those estimated from the reduction of heterozygosity.

Departures from Hardy-Weinberg proportions at the allozyme loci were detected by means of the $f$ statistic and the chi-square test (table 1). Statistically significant deviations from Hardy-Weinberg expectations are confined to the 18-month-old oyster sample, and they occur at four of the five loci (Est-3, Mdh-1, Pgi, Pgm). This suggests that they are generated either at the time of fertilization, during the planktonic stage or at the earlier postsettlement stage. Two loci, Est-3 and Pgm, show a heterozygote excess, while the others present strong heterozygote deficiencies. The heterozygote excess of the Est-3 locus is due to the absence of Est $-3^{1} /$ Est $-3^{1}$ homozygote a phenomenon noticed by Wilkins and Mathers (1973) in Irish and Saavedra et al. (1987) in Spanish populations. The heterozygote excess at the Pgm locus could be originated either by different allelic frequencies between males and females, a very probable situation given the "founder effect" occurring in the foundation of the cohort, or viability selection. The heterozygote deficiencies at $M d h-1$ and $P g i$ loci could be explained, at first, in terms of inbreeding, null alleles, Wahlund effect or selection. Zouros and Foltz $(1984 a, b)$ have deeply discussed the heterozygote deficiency in bivalve molluscs where it is a very usual phenomenon. The heterogeneity of the heterozygote deficiencies among loci argues 


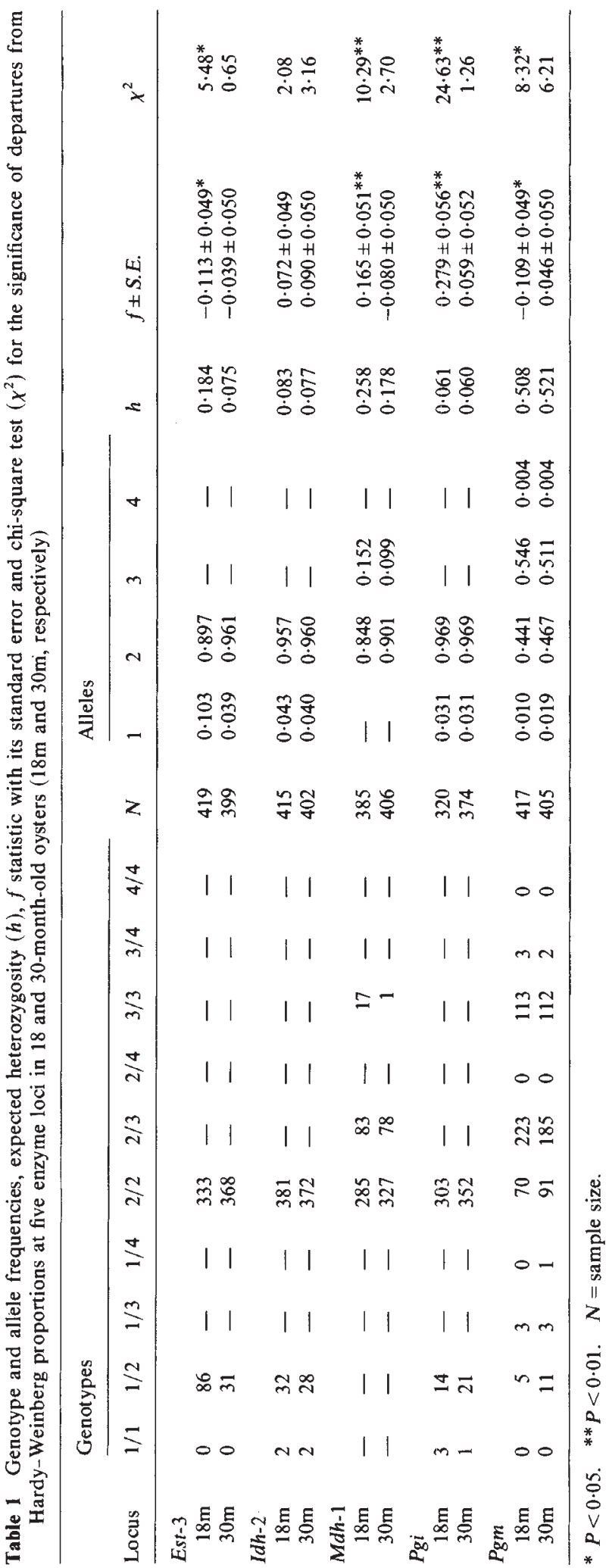


Table 2 Mean weights and post-settlement relative viabilities with their standard errors of single-locus genotypes at five enzyme loci. The more frequent allele is denoted by " $a$ ", and "b" represents the allele following in frequency. Numbers of individuals are given in parentheses

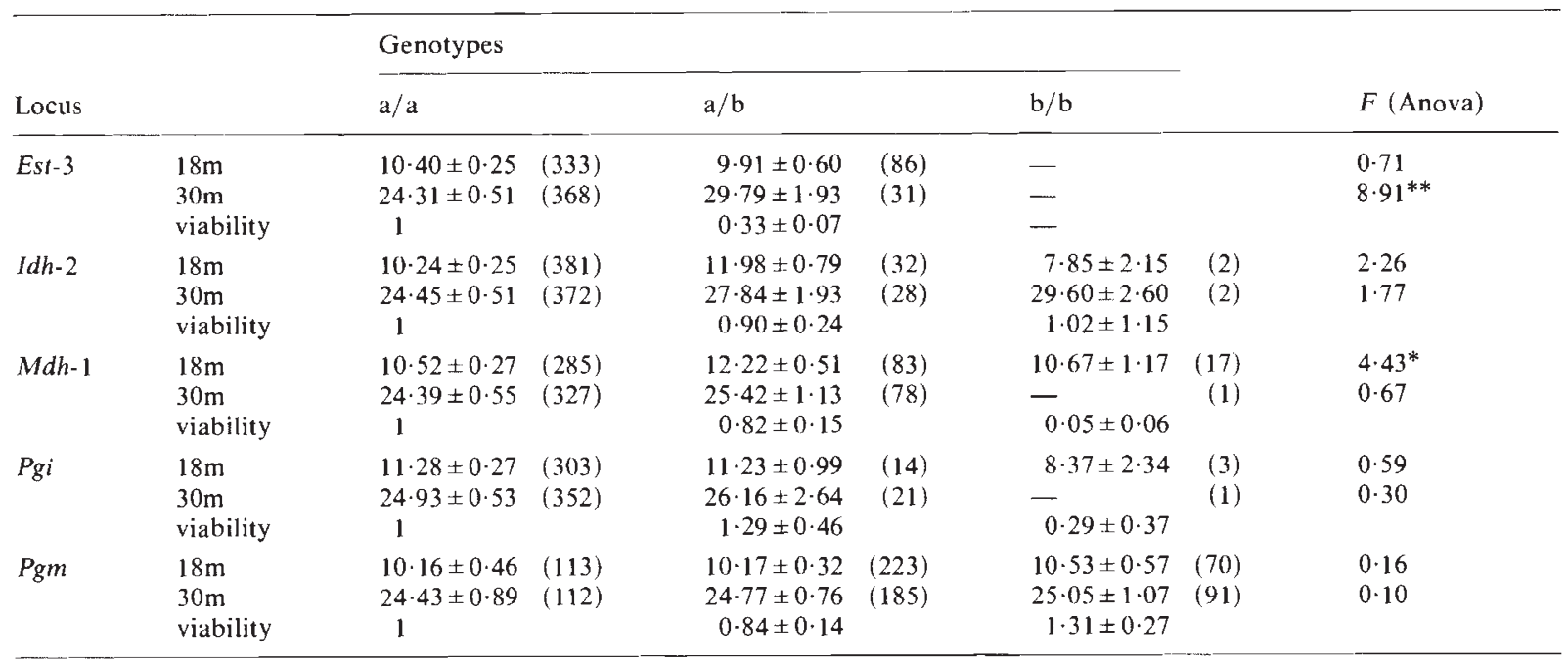

$* P<0.05 .18 \mathrm{~m}=18$-month-old oysters.

** $P<0.01 .30 \mathrm{~m}=30$-month-old oysters.

against a simple inbreeding hypothesis (consanguineous matings within the parental population), while the Wahlund effect can be discarded given that the loci with higher geographic genetic differentiation do not seem to present higher heterozygote deficiencies (Zouros and Foltz, $1984 a, b$; Saavedra et al. 1987). This leaves natural selection as the most likely agent promoting the heterozygote deficiencies, either through viability selection or subdivision generated by the occurrence of genotypes with different timing of spawning (genotype-dependent spawning). The condition for genotype distributions exhibiting departures from Hardy-Weinberg proportions due to viability selection is $W_{1} \times W_{3} \neq W_{2}^{2}$, where $W_{1}, W_{2}$ and $W_{3}$ are the viabilities corresponding to the genotypes $A_{1} A_{1}, A_{1} A_{2}$ and $A_{2} A_{2}$, respectively (Lewontin and Cockerham, 1959; Li, 1959; Workman, 1969). When $W_{1} \times W_{3}<W_{2}^{2}$ a heterozygote excess will be present, while if $W_{1} \times W_{3}>W_{2}^{2}$ there will be a deficiency of heterozygotes.

Table 2 displays the mean weights and the relative viabilities for genotypes at single allozyme loci. At the Pgm locus only the two more frequent alleles are considered. The analysis of variance of individual weights for each locus show statistically significant differences among genotypes only for Est-3 (30-month-old sample) and $M d h-1$ (18month-old sample). In both cases, the heterozygote is the genotype with a higher growth rate. In the other cases, the heterozygote is not always the genotype with a higher mean weight. Viability in table 2 is the postsettlement survival in the interval from 18 to 30 months measured by means of the cross-product ratio estimator. Postsettlement viabilities are given relative to the homozygote for the more frequent allele and with their standard errors computed from the asymptotic sampling variances (see Material and Methods). The large variances associated with the fitness estimates reduces the power for detecting statistical differences between viability estimates. However, in spite of this, a certain trend is observed since the heterozygoes present, in general, lower viability values (Est-3,Idh-2 and Pgm loci). On the contrary, at the $P g i$ locus, the heterozygote is the fittest genotype, and at the $M d h-1$ locus the heterozygote is intermediate in fitness value. An outstanding fact is the occurrence of several deleterious genotypes which present a clear reduction of viability and have in common the presence of alleles that are not the more frequent. Examples are the Est $-3^{1} / E s t-3^{2}$ heterozygote with a viability of $0.33 \pm 0 \cdot 07$, the $M d h-1^{3} / M d h-1^{3}$ homozygote $(0.05 \pm 0.06)$ and the $P g i^{1} / P g i^{1}$ homozygote $(0 \cdot 29 \pm 0 \cdot 37)$.

\section{Multilocus allozyme heterozygosity and growth rate}

Five-locus genotypes were determined for 28218 month-old individuals and 359 30-month-old 


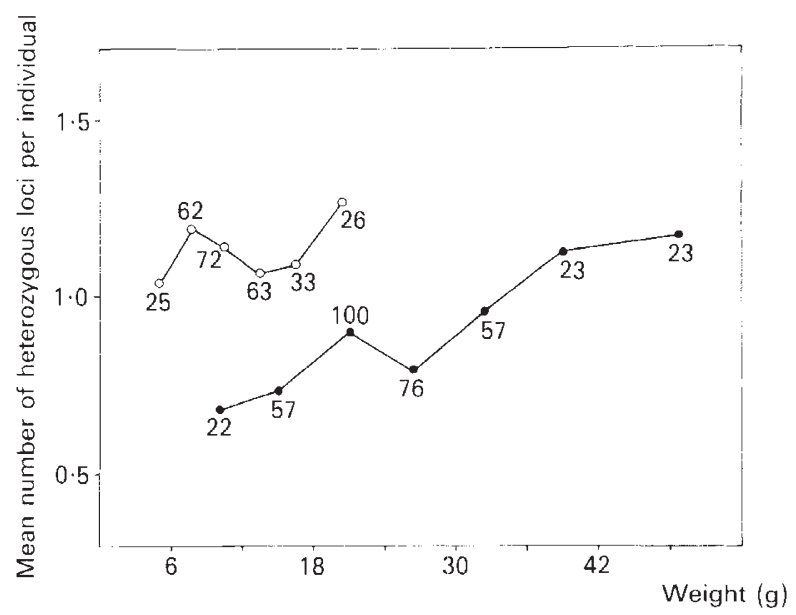

Figure 2 Relationship between average individual heterozygosity and mean weight within size classes in $18(\mathrm{O})$ and 30 (O) -month-old oysters. Numbers in the figure are sample sizes.

individuals. The correlation among individuals between weight and the number of heterozygous loci was $0.038(P>0.05)$ and $0.146(P<0.01)$ at the 18 and 30 -month age classes, respectively. The non parametric correlation coefficient of Kendall $(\tau)$ was $0.014(P>0.05)$ and $0.093(P<0.01)$ at the two age classes. This means that about 2 per cent of the variability in weight among individuals is explained by the differences in multilocus heterozygosity in the 30 -month-old oysters. This result is very similar to those found in $C$. virginica (Zouros et al., 1980), and in the mussel
M. edulis (Koehn and Gaffney, 1984). The average of the number of heterozygous loci per individual within each weight class and mean weight present obviously a higher correlation $(r=0.506, P>0.05$, and $r=0.946, P<0.01$, at 18 and 30 -month age classes; fig. 2). Therefore, a statistically significant positive correlation between growth rate and number of heterozygous loci per individual occurs at 30 -month-old oysters and a similar but not significant trend seems to be present at 18-month-old individuals. From these results it is observed that the heterozygosity-growth correlation appears to increase with age in $O$. edulis. The increase of correlation with age is an unusual observation and it has only been reported in pitch pine by Ledig et al. (1983).

The contribution of individual loci to the heterozygosity-growth correlation can be studied by computing the observed heterozygosity within each of the weight classes for each locus (table 3 ). For each one of the five loci there is a positive correlation between the observed heterozygosity and growth rate in the 18 -month-old oysters. Both $M d h-1$ and $I d h-2$ loci present a strong and statistically significant correlation $(r=0.947, P<0.01$, and $r=0.942, P<0.01$, respectively). $P g m, P g i$ and Est-3 present non-statistically significant correlations $(r=0.581, \quad r=0.191$ and $r=0.059$, respectively, $P>0.05$ ). In the sample of 30 -monthold oysters, all the studied loci but $\mathrm{Pgm}(r=$ $-0.048, P>0.05)$ present a positive heterozygosity-growth correlation. Both $I d h-2$ and Est-3 are the loci that show the strongest correlation $(r=$ $0 \cdot 916, P<0 \cdot 01$, and $r=0 \cdot 803, P<0 \cdot 05$, respectively). Pgi and $M d h-1$ do not display a statistically

Table 3 Observed heterozygosities inside weight classes at five enzyme loci in 18 and 30 -month-old oysters

\begin{tabular}{|c|c|c|c|c|c|c|}
\hline $\begin{array}{l}\text { Weight } \\
\text { class (g) }\end{array}$ & Est -3 & $I d h-2$ & $M d h-1$ & $P g i$ & Pgm & mean \pm S.E. \\
\hline \multicolumn{7}{|c|}{ 18-month-old } \\
\hline $0-3$ & 0.154 & 0.000 & 0.143 & 0.000 & 0.500 & $0.192 \pm 0.028$ \\
\hline $3-6$ & 0.263 & 0.038 & 0.094 & 0.025 & 0.550 & $0.223 \pm 0.011$ \\
\hline $6-9$ & 0.250 & 0.077 & $0 \cdot 193$ & 0.029 & 0.565 & $0.234 \pm 0.009$ \\
\hline $9-12$ & $0 \cdot 174$ & 0.087 & 0.223 & 0.066 & 0.582 & $0.231 \pm 0.009$ \\
\hline $12-15$ & 0.135 & 0.080 & 0.253 & 0.057 & 0.552 & $0.219 \pm 0.010$ \\
\hline $15-18$ & $0 \cdot 154$ & 0.105 & 0.256 & 0.056 & 0.541 & $0.222 \pm 0.012$ \\
\hline$>18$ & $0 \cdot 276$ & $0 \cdot 138$ & $0 \cdot 345$ & 0.000 & 0.585 & $0.274 \pm 0.016$ \\
\hline \multicolumn{7}{|c|}{ 30-month-old } \\
\hline $6-12$ & 0.000 & 0.034 & $0 \cdot 219$ & 0.036 & 0.484 & $0 \cdot 160 \pm 0 \cdot 015$ \\
\hline $12-18$ & 0.030 & 0.058 & $0 \cdot 130$ & 0.082 & 0.529 & $0 \cdot 168 \pm 0 \cdot 010$ \\
\hline $18-24$ & 0.098 & 0.071 & $0 \cdot 188$ & 0.059 & 0.513 & $0.189 \pm 0.007$ \\
\hline $24-30$ & 0.024 & $0 \cdot 060$ & 0.188 & 0.038 & 0.460 & $0.156 \pm 0.008$ \\
\hline $30-36$ & $0 \cdot 103$ & 0.069 & 0.259 & 0.018 & 0.534 & $0.197 \pm 0.011$ \\
\hline $36-42$ & $0 \cdot 250$ & 0.120 & 0.240 & 0.083 & 0.400 & $0.219 \pm 0.010$ \\
\hline$>42$ & $0 \cdot 167$ & 0.125 & 0.167 & $0 \cdot 130$ & 0.542 & $0.227 \pm 0.015$ \\
\hline
\end{tabular}


significant correlation $(r=0.548$ and $r=0 \cdot 190$, respectively, $P>0.05)$.

In order to investigate the causes of the heterozygosity-growth relationship it is necessary to perform a different analysis of correlation. Thus, Smouse (1986) has pointed out that a linear regression among individuals between the logarithm of the growth rate and the adaptive distance, a value estimated from the equilibrium allozymic frequencies, will be established if growth rate is the major component of the total selection maintaining the allozyme polymorphisms. The main assumptions of the adaptive-distance model are multiplicative overdominance, unlinked loci and growth rate as a surrogate measure of fitness (see Smouse, 1986, and Bush et al., 1987 for details). The critical point is that Smouse's model assumes that the heterozygote superiority of the allozyme loci (due to overdominance of the enzyme loci or associative overdominance of closely linked loci) is the cause of the heterozygosity-growth correlation. Therefore, if the heterozygosity-growth correlation is directly related to the maintenance of the allozyme polymorphisms, then Smouse's model has to account for a level of variation in growth rate higher than that explained by the standard regression analysis. On the contrary, if protein loci are themselves selectively neutral and the observed heterozygosity is merely indicative of the degree of genomic heterozygosity, as it is assumed under an inbreeding hypothesis (see Leding et al., 1983; Smouse, 1986; Bush et al., 1987), then Smouse's model will not suppose an improvement on the standard regression analysis. In our case, the correlation coefficients estimated by the adaptive-distance model are -0.087 ( $P>$ $0 \cdot 05)$ and $-0.189(P<0.01)$ for 18 and 30 monthold oysters, respectively. The minus sign means that heterozygotes are the more fit genotype by which only the absolute value of the correlation must be taken in consideration. These values are clearly higher than those corresponding to the correlations between growth rate and number of heterozygous loci per individual $(r=0.038$, and $r=0 \cdot 146$, for 18 and 30 -month-old oysters, respectively). The correlation coefficient estimated by Smouse's method in the younger oysters is more than twice that obtained by standard regression analysis. However, it is necessary to take into consideration that more parameters are used in the adaptive-distance analysis. Hence, our results are not conclusive evidence that the adaptive-distance model gives a significant improvement with respect to the standard analysis and is, therefore, a more efficient model.

\section{Multilocus allozyme heterozygosity and viability}

Relative viabilities for multilocus genotypes at allozyme loci can easily be estimated by comparing the genotypic distributions of the two age classes (18 and 30-month-old oysters) by means of the cross-product ratio estimator. In this way, viability fitness estimates with their standard errors based on the asymptotic sampling variances (see Material and Methods) are obtained for individuals differing in their degree of heterozygosity (number of heterozygous loci per individual, fig. 3 and Table 4). A strong negative correlation between postsettlement viability and heterozygosity is found in $O$. edulis $(r=-0.998, P<0.05)$. More heterozygous individuals present a lower relative viability. Heterozygous individuals at 3 loci present a viability of $0 \cdot 29 \pm 0.13$ relative to the homozygous individuals (fitness equal to 1 ) and the mean viability of the heterozygotes for 1,2 and 3 loci is $0 \cdot 51 \pm 0 \cdot 12$ (mean \pm empirical error based on replicates).

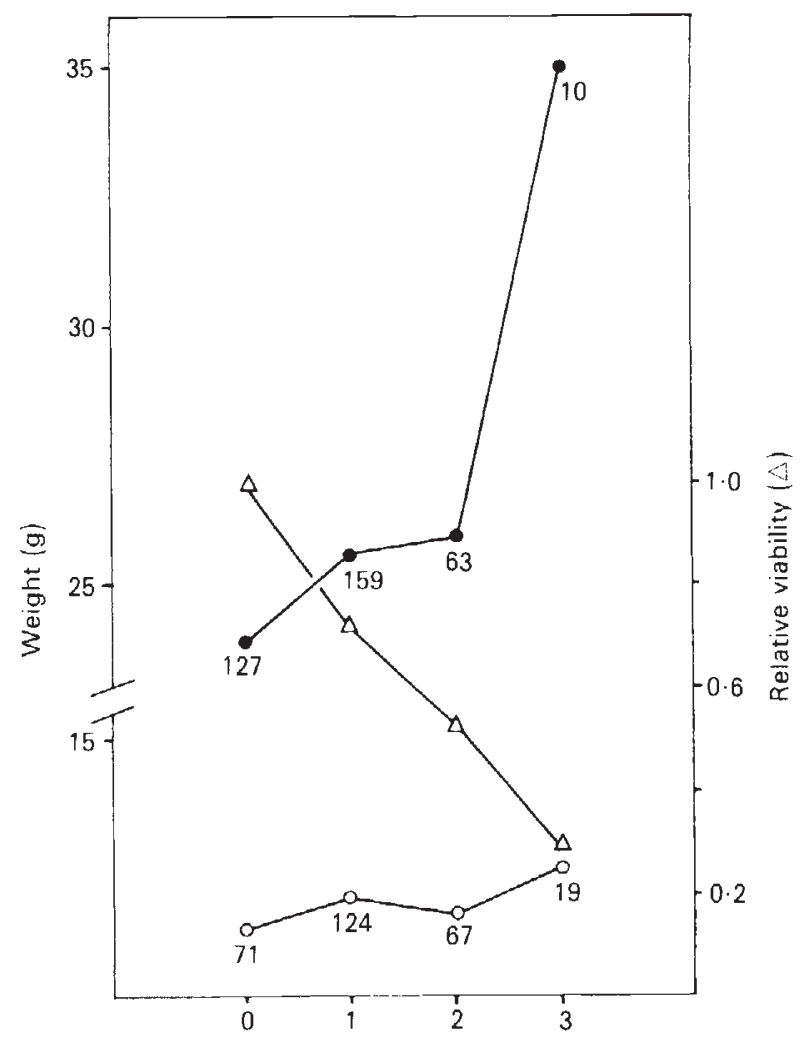

No. of heterozygous loci per individual

Figure 3 Mean weight in $18(0)$ and $30(0)$-month-old oysters and postsettlement relative viability $(\Delta)$ as a function of the number of heterozygous loci per individual. 


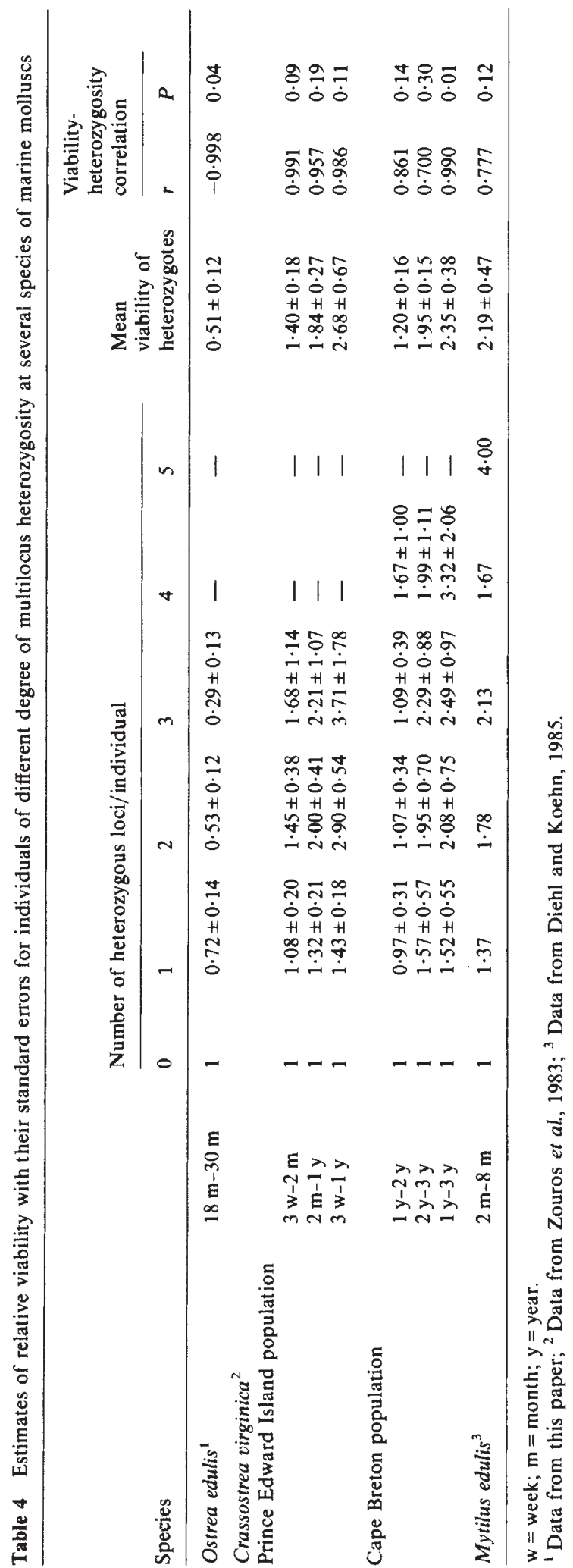


Estimation of postsettlement relative viabilities for individuals differing in their degree of allozyme heterozygosity was also carried out in other species of marine molluses such as $C$. virginica and $M$. edulis from published data (table 4 ). We have computed these fitness estimates by means of the cross-product ratio estimator and their standard errors are based on the asymptotic sampling variances. In this context, it should be pointed out that the viability index employed by Zouros et al. (1983) for estimating postsettlement viability in $C$. virginica is not appropriate for measuring survival quantitatively. This index measures the viability of the $i$ th genotype as $\hat{V}_{i}=\left(n_{2 i}-n_{1 i}\right) /\left(n_{1 i}\right)$. Hence, it is not appropriate for measuring viability as probability of survival or fitness since it really measures the ratio of the relative viability to the mean fitness minus one $\left(\hat{V}_{i}=W_{i} / \bar{W}-1\right)$. In table 4 the cross-product ratio viability estimates in $C$. virginica are computed from the frequency distributions of heterozygosity classes given by Zouros et al. (1983) which include the leucine aminopeptidase-2 (Lap-2), phosphoglucose isomerase (Pgi) and phosphoglucomutase $(\mathrm{Pgm})$ loci for the 3week and 2-month-old age classes from the Prince Edward Island population and the glutamate oxaloacetate transaminase (Got-1), esterase-3 (Est-3), Lap-2 and Pgi loci for the 1-year-, 2-yearand 3-year-old cohorts from Cape Breton. Postsettlement viabilities include the periods: 3 -weeks to 2-months, 2-months to 1-year, 1-year to 2-years, and 2-years to 3-years: In $M$. edulis viability fitnesses are estimated from heterozygosity distributions shown graphically in fig. 4 of Diehl and Koehn (1985), and therefore they are approximate values which are given without standard errors in table 4. The loci used in the study of $M$. edulis are aminopeptidase-I ( $L a p$ ), octopine dehydrogenase $(O d h)$, leucyl-alanyl dipeptide hydrolase $(A p)$, $P g m$ and Pgi (Diehl and Koehn, 1985).

In the three species, $O$. edulis, $C$. virginica and $M$. edulis, a clear correlation between viability and allozyme heterozygosity is observed (table 4). Moreover, the existence of important viability differences associated with allozyme heterozygosity is apparent. In $O$. edulis, the correlation is negative, but in the two populations of $C$. virginica and the mussel $M$. edulis the correlations are always positive and more heterozygous individuals enjoy a greater relative viability. The estimates of the correlation coefficients are always large, although in some cases they are not statistically significant due to the few degrees of freedom of the tests $(r=-0.998, \mathrm{df}=1, P=0.04$ for $O$. edulis; $r=0.986, \mathrm{df}=1, P=0.11$ for the Prince Edward
Island population and $r=0.990 . \mathrm{df}=2, P=0.01$ for the Cape Breton population of $C$. virginica; $r=0.772, \mathrm{df}=3, P=0.12$ for $M$. edulis). The fitness estimates for postsettlement viability have large variances and this reduces the statistical power to detect significant differences. Thus, taking $\left|\hat{W}_{i}-1\right|>(2$ standard errors) as the criterion for significance at the 0.05 level, the majority of the heterozygosity classes present viability estimates not significantly different from 1 . However, the fitness estimates are very large, so that the averages of the estimates of the heterozyges are statistically different from 1 in the great majority of cases (7 out of 8 cases). In the American oyster the heterozygous individuals attain a mean viability of $2.68 \pm 0.67$ (mean \pm empirical error) for the period of three weeks to one year for Prince Edward Island population, and $2.35 \pm 0.38$ from one year to three years in Cape Breton population. In $M$. edulis the mean viability of heterozygotes is $2 \cdot 19 \pm$ 0.47 from two months to eight months. In terms of selection coefficients against the less fit individuals relative to the more fit ones, the estimates range from 0.28 to 0.71 with an average selection coefficient of $0.49 \pm 0.12$ (mean \pm empirical error) for the European oyster (note that in this case the homozygotes are the more fit individuals). In the American oyster, estimates of selection coefficients range from 0.22 to 0.73 with a mean of $0.52 \pm 0.16$ for the period three-weeks to one-year and 0.25 to 0.70 with a mean of $0.47 \pm$ 0.10 for the period one-year to three-years. In the mussel $M$. edulis, selection coefficients range from 0.47 to 0.75 with a mean value of $0.60 \pm 0.05$.

\section{DISCUSSION}

In the studied cohort of $O$. edulis, a relationship between growth rate and multilocus heterozygosity for five polymorphic enzyme loci is detected. This relationship is manifested by a positive heterozygosity-growth correlation increasing with the age of individuals. So, this correlation is statistically non significant for younger oysters (18-month age class) but clearly significant for 30-month-old oysters. Heterozygosity at electrophoretic loci explains about the 2 per cent of the variation in weight among 30-month-old individuals. This value is slightly less than those reported by Zouros et al. (1980) for the American oyster, C. virginica, and Koehn and Gaffney (1984) for the mussel $M$. edulis.

The incidence of those factors determining the genetic structure of the cohort on the correlation detected in $O$. edulis deserves consideration. Thus, 
inbreeding can cause or enhance the heterozygosity-fitness correlation (Strauss, 1986), while "founder effects" can obscure it (Gaffney and Scott, 1984). In addition, it has been suggested that inbreeding could be responsible for the heterozygosity-fitness correlations in those species in which deficiencies of heterozygotes in relation to HardyWeinberg expectations are observed (Strauss, 1986). Deficiencies of heterozygotes occur in the American oyster and the mussel M. edulis (Gartner-Kepkay et al., 1980, 1983; Zouros and Foltz, $1984 a, b)$, as well as in $O$. edulis. However, it is not likely that the deficiencies of heterozygotes noticed in marine molluscs are a consequence of a consanguineous breeding structure as marine molluscs, including $O$. edulis, have pelagically dispersed larvae (see Zouros and Foltz, 1984a, b). Moreover, the departures from Hardy-Weinberg proportions among loci are very heterogeneous in sign and magnitude in $O$. edulis contrarily to the expectations under a consanguineous breeding structure. Consequently, it appears that the correlation between growth rate and heterozygosity detected in $O$. edulis is not due to consanguineous matings occurring in populations of this species.

"Founder effects" could also affect the heterozygosity-fitness correlation detected in $O$. edulis. In fact, several studies of marine molluscs conducted with individuals from a limited number of parents have failed to show any effect of heterozygosity on growth rate (Beaumont et al., 1983, with M. edulis; Adamkewicz et al., 1984, with Mercenaria mercenaria; Gaffney and Scott, 1984, with $M$. lateralis, $C$. virginica and Spisula solidissima), an outcome attributed to founder events (Gaffney and Scott, 1984; Koehn and Gaffney, 1984). The cohort of $O$. edulis studied here was a cultured population in which a "founder effect" was detected through a reduction at the allozyme heterozygosity in relation to the parental population and it was probably caused when larvae were produced in the hatchery. However, in our case, the "founder effect" must have a minor effect on the heterozygosity-growth relationship given that a correlation was indeed detected. In the light of the studies cited above, if the "founder effect" had an influence on the correlation detected in the cohort this would be in the sense of underestimating the correlation occurring in the natural population.

In the present paper, both growth rate and viability are jointly studied in the $O$. edulis cohort and an estimation of viability fitnesses has been carried out. To date, only a few studies have investigated the relationship between viability and multilocus allozyme heterozygosity and, in most cases, estimation of viability fitnesses for individuals differing in their degree of heterozygosity has not been carried out (see Introduction). In $O$. edulis, fitness estimation for postsettlement viabilities shows as differences in fitness among multilocus allozyme genotypes can be detected due to a cumulative effect of the loci. In this case, a strong negative correlation between heterozygosity and viability is detected. More heterozygous oysters present a lower viability and large differences in fitness estimates are observed (the mean viability of heterozygote oysters for 1,2 and 3 loci is $0.51 \pm$ $0 \cdot 12$ ). This negative correlation between viability and heterozygosity is an unexpected result that must be interpreted with caution. It could be related to the high mortalities occurring in the natural populations of European oyster located on the coasts of the NW of Spain. Actually, it is not completely known what is the cause of these mortalities but it seems clear that several parasites such as the haplosporidium Bonamia ostreae are involved (Montes et al., 1988). In the studied cohort 57 per cent of the individuals died during the interval in which the oysters were growing from 18 to 30-month-age and the occurrence of $B$. ostreae was detected. Empirical observations point out that the heavier oysters present an increased mortality and it is probably due to a preference of the parasites for these individuals (Guerra and Montes, personal communication). Therefore, the observed negative correlation between viability and heterozygosity could be due to a positive association between infestation and weight.

The correlations between multilocus heterozygosity and survival observed in $C$. virginica (Zouros et al., 1983) and M. edulis (Diehl and Koehn, 1985) have been also quantified in this paper in terms of Darwinian fitness by means of the estimation of the postsettlement viabilities for individuals differing in their degree of allozyme heterozygosity (table 4). The important subject to take into consideration is that, although the estimates of viability present large variances, a cumulative effect of allozyme heterozygosity on viability is detected and important selective differences appear to be associated to allozyme heterozygosity (the average viability of heterozygotes at one or more loci is $0.51 \pm 0.12$ in $O$. edulis, $2.68 \pm 0.67$ for the period of three-weeks to one-year and $2 \cdot 35 \pm$ 0.38 from one-year to three-years for the Prince Edward Island and the Cape Breton populations, respectively, in $C$. virginica, and $2 \cdot 19 \pm 0 \cdot 47$ from two-months to eight-months in $M$. edulis). In terms of selection coefficients against the less fit 
individuals the average selective coefficients are $0 \cdot 49 \pm 0 \cdot 12$ for $O$. edulis, $0 \cdot 52 \pm 0 \cdot 16$ and $0.47 \pm 0 \cdot 10$ for the Prince Edward and the Cape Breton populations of $C$. virginica, and $0.60 \pm 0.05$ for M. edulis. Therefore, the estimation of viability fitnesses shows that the correlation between heterozygosity and viability is established through large selective differences. These differences are still more impressive if it is considered that they correspond to heterozygosities at only 3-5 allozyme loci. It would be very interesting to know whether we are dealing with a general phenomenon or a particular situation restricted to the studied bivalves. In species where a correlation between heterozygosity and age has been detected as the scallop P. magellanicus (Foltz and Zouros, 1984), the clam $M$. balthica (Green et al., 1983), the marine fish $F$. heteroclitus (Mitton and Koehn, 1975), the plaice $P$. platessa (Beardmore and Ward, 1977) and the perennial herb L. cylindracea (Schaal and Levin, 1976) is not known whether this correlation is established through large selective differences in viability such as those reported in this study. Consequently, at this moment the generality of our findings remains to be determined.

From another perspective, the results presented in this paper suggest that the nature of the heterozygosity-fitness correlation might be very different according to the fitness trait considered. In the three species in this study, $O$. edulis, C. virginica and $M$. edulis, the magnitude of the relationship between heterozygosity and viability clearly appears to be higher than that corresponding to the relationship between heterozygosity and growth rate. Our results with $O$. edulis and those of Zouros et al. (1980) with C. virginica and Koehn and Gaffney (1984) with $M$. edulis show that in these species allozyme heterozygosity explains 2-4 per cent of the variability in growth rate among individuals, while the estimation of viability fitness for heterozygosity classes carried out in this paper shows that the heterozygosity is associated with large differences in postsettlement viability in the three species of bivalves. This contrast between viability and growth rate could be relevant in connection with the genetic mechanism underlying the heterozygosity-fitness relationship.

To date, three main hypotheses have been advanced to explain the heterozygosity-fitness correlation (see Ledig et al., 1983; Mitton and Grant, 1984; Mallet et al., 1986; Smouse, 1986; Bush et al., 1987; Zouros and Foltz, 1987; Koehn et al., 1988; Zouros et al., 1988). The overdominance hypothesis supposes that allozyme loci have themselves a direct effect on fitness. Alternatively, elec- trophoretic loci could be neutral genes in gametic disequilibrium with closely linked selective loci (associative overdominance hypothesis) or neutral markers of the degree of genomic heterozygosity (inbreeding depression hypothesis). The overdominance hypothesis is partially supported by experiments that show an inverse relationship between allozyme heterozygosity and the energetic costs of metabolism measured by standard rates of oxygen consumption in species as $C$. virginica and M. lateralis (Koehn and Shumway, 1982; Garton et al., 1984). Recently, Koehn et al. (1988) have demonstrated that a particular physiological category of loci, as those determining enzymes involved in protein catabolism and glycolysis, presents the highest correlations with growth rate in M. lateralis. On this basis, Koehn et al. (1988) have claimed that allozyme heterozygosity directly affects growth rate, and, evidently, it is likely that a small number of allozyme loci may produce an effect of about 4 per cent of the variation in growth rate. However, it is necessary to underline that it is not conceivable for a small number of allozyme loci to produce selective differences in viability such as those reported in this paper for the three species of bivalves studied. Obviously, a heterozygosity-viability correlation associated to mean selection coefficients in survival in a range close to 0.50 cannot be produced by a few allozymes and, consequently, loci other than the monitored allozymes must be contributing to this correlation. Therefore, a simple overdominance hypothesis of the monitored allozyme loci can be ruled out and other mechanisms such as associative overdominance must be invoked to explain the heterozygosity-viability correlation. The rationale of this explanation is not in contradiction with the experimental evidence derived from the investigations with growth rate, since allozymes may themselves be responsible for differences in developmental rate and, however, they might serve as genetic markers in relation to viability. Growth rate and viability are two different traits that could be controlled by different sets of genes by which the possibility of different genetic mechanisms for the correlations of allozyme heterozygosity with viability and growth could be a likely explanation. Finally, it is necessary to point out that our results do not exclude that the monitored allozymes affect viability, but they suggest that the observed effects on viability are mainly due to other loci. The possible effect of allozymes on viability is an open question that must be answered by means of new experimental approaches. In this sense, a combined study of both growth rate and viability for 
a large number of polymorphic enzymes belonging to different physiological and biochemical categories could shed light on this subject.

Acknowledgements This work was supported by a grant from the Consellería de Educación e Ordenación Universitaria, Xunta de Galicia (Spain).

\section{REFERENCES}

ADAMKEWICZ, L., TAUB, S. R. AND WALL, J. R. 1984. Genetics of the clam Mercenaria mercenaria. II. Size and genotype. Malacologia, 25, 525-533.

Alvarez, G., SANTOS, M. AND ZapatA, C. 1984. Frequencydependent selection arising from inappropriate fitness estimation. Evolution, 38, 696-699.

ANXOlabéHĖRE, D., GoUX, J. M. AND PERIQUET, G. 1982. A bias in estimation of viabilities from competition experiments. Heredity, 48, 271-282.

BEARDMORE, J. A. AND WARD, R. D. 1977. Polymorphism, selection, and multi-locus heterozygosity in the plaice, Pleuronectes platessa L. In Christiansen, F. B. and Fenchel, T. M. (eds) Measuring Selection in Natural Populations, Springer-Verlag, New York, pp. 207-221.

BEAUMONT, A. R., BEVERIDGE, C. M. AND BUDD, M. D. 1983. Selection and heterozygosity within single families of the mussel Mytilus edulis (L.). Mar Biol. Lett., 4, 151-161.

BUSH, R. M., SMOUSE, P. E. AND LEDIG, F. T. 1987. The fitness consequences of multiple-locus heterozygosity: The relationship between heterozygosity and growth rate in pitch pine (Pinus rigida Mill.). Evolution, 41, 787-798.

CONNOLLY, J. AND GLIDDON, G. 1984. On the estimation of viabilities in competition experiments. Heredity, 53, 527543.

COOK, L. M. 1971. Coefficients of Natural Selection. Hutchinson Univ. Library, London.

CROW, J. F. AND KIMURA, M. 1970. An Introduction to Population Genetics Theory. Harper \& Row, Publishers, New York.

DIEHL, W. J. AND KOEHN, R. K. 1985. Multiple-locus heterozygosity, mortality, and growth in a cohort of Mytilus edulis. Mar. Biol., 88, 265-271.

ELANDT-JOHNSON, R. C. 1971. Probability Models and Statistical Methods in Genetics. John Wiley \& Sons, New York.

FOLTZ, D. W., NEWKIRK, G. F. AND ZoUROS, E. 1983. Genetics of growth rate in the American oyster: Absence of interactions among enzyme loci. Aquaculture, 33, 157-165.

FOLTZ, D. W. AND ZOUROS, E. 1984. Enzyme heterozygosity in the scallop Placopecten magellanicus (Gmelin) in relation to age and size. Mar. Biol. Lett., 5, 255-263.

FUJIO, Y. 1982. A correlation of heterozygosity with growth rate in the Pacific oyster, Crassostrea gigas. Tohoku J. Agric. Res., 33, 66-75.

GAFFNEY, P. M. AND SCOTT, T. M. 1984. Genetic heterozygosity and production traits in natural and hatchery populations of bivalves. Aquaculture, 42, 289-302.

GARTNER-KEPKAY, K. E., DICKIE, L. M., FREEMAN, K. R. AND ZOUROS, E. 1980. Genetic differences and environments of mussel populations in the maritime provinces, Can. J. Fish. Aquat. Sci., 37, 775-782.

GARTNER-KEPKAY, K. E., ZOUROS, E., DICKIE, L. M. AND FREEMAN, K. R. 1983. Genetic differentiation in the face of gene flow: A study of mussel populations from a single Nova Scotian embayment. Can. J. Fish. Aquat. Sci., 40, 443-451.
GARTON, D. W., KOEHN, R. K. AND SCOTT, T. M. 1984. Multiplelocus heterozygosity and the physiological energetics of growth in the coot clam, Mulinia lateralis, from a natural population. Genetics, 108, 445-455.

GREEN, R. H., SINGH, S. M., HICKS, B. AND MCCUAIG, J. 1983. An artic intertidal population of Macoma balthica (Mollusca, Pelecypoda): Genotypic and phenotypic components of population structure. Can. J. Fish. Aquat. Sci, 40, 1360-1371.

KOEHN, R. K., DIEHL, W. J. AND SCOTT, T. M. 1988. The differential contribution by individual enzymes of glycolysis and protein catabolism to the relationship between heterozygosity and growth rate in the coot clam, Mulinia lateralis. Genetics, 118, 121-130.

KOEHN, R. K., AND GAFFNEY, P. M. 1984. Genetic heterozygosity and growth rate in Mytilus edulis. Mar. Biol., 82, 1-7.

KOEHN, R. K. AND SHUMWAY, S. E. 1982. A genetic/physiological explanation for differential growth rate among individuals of the American oyster Crassostrea virginica (Gmelin). Mar. Biol. Lett., 3, 35-42.

LEDIG, F. T., GURIES, R. P. AND BONEFELD, B. A. 1983. The relation of growth to heterozygosity in pitch pine. Evolution, 37, 1227-1238.

LEWONT'N, R. C., AND COCKERHAM, C. C. 1959. The goodnessof-fit test for detecting natural selection in random mating populations. Evolution, 13, 561-564.

LI, C. C. 1959. Notes on relative fitness of genotypes that forms a geometric progression. Evolution, 13, 564-567.

LI, C. C., AND HORVITZ, D. 1953. Some methods of estimating the inbreeding coefficient. Am. J. Human Genet., 5, 107117.

MALLET, A. L., ZOUROS, E. K., GARTNER-KEPKAY, E. AND FREEMAN, K. R. 1986. Genetics of growth in blue mussels: family and enzyme-heterozygosity effects. Mar. Biol., 92, 475-482.

MILLAR, R. H. 1961. Scottish oyster investigations 1946-1958. Depart. Agric. and Fish for Scotland Mar. Res., 3, 1-76.

MITTON, J. B. AND GRANT, M. C. 1984. Associations among protein heterozygosity, growth rate, and developmental homeostasis. Ann. Rev. Ecol. Syst., 15, 479-499.

MITTON, J. B. AND KOEHN, R. K. 1975. Genetic organization and adaptative response of allozymes to ecological variables in Fundulus heteroclitus. Genetics, 79, 97-111.

MONTES, J., ACOSTA, C. P. AND GUerRA, A. 1988. Oyster mortality in Galicia (N. W. Spain). In De Pauw, N., Jaspers, E., Ackefors, H. and Wilkins, N. (eds) Proceedings Aquaculture Europe '87. (In press).

MUKAI, T., WATANABE, T. K. AND YAMAGUCHI, O. 1974. The genetic structure of natural populations of Drosophila melanogaster. XII. Linkage disequilibrium in a large local population. Genetics, 77, 771-793.

NEI, M. 1975. Molecular Population Genetics and Evolution. North-Holland, Amsterdam.

NEI, M. 1978. Estimation of average heterozygosity and genetic distance from a small number of individuals. Genetics, 89 , 583-590.

ROBERTSON, A. AND HILl, W. G. 1984. Deviations from HardyWeinberg proportions: sampling variances and use in estimation of inbreeding coefficients. Genetics, 107, 703-718.

RODHOUSE, P. G., MCDONALD, J. H., NEWELl, R. I. E. AND KOEHN, R. K. 1986. Gamete production, somatic growth and multiple-locus enzyme heterozygosity in Mytilus edulis. Mar. Biol., 90, 209-214.

ROMAN, G. 1987. Estudio sobre acondicionamiento de la ostra plana (Ostrea edulis L.). Cuad. Marisq. Publ. Tec., 9, 13-39. 
SAAVEDKA, C., ZAPATA, C., GUERRA, A. AND ALVAREZ, G. 1987. Genetic structure of populations of flat oyster (Ostrea edulis "Linneo, 1758") from the NW of the Iberian Peninsula. Inv. Pesq., 51, 225-241.

SCHAAL, B. A. AND LEVIN, D. A. 1976. The demographic genetics of Liatris cylindracea Michx. (Compositae). Amer. Natur., 110, 191-206.

SINGH, S. M. AND ZOUROS, E. 1978. Genetic variation associated with growth rate in the American oyster (Crassostrea virginica). Evolution, 32, 342-353.

SINGH, S. M. AND ZOUROS, E. 1981. Genetics of growth rate in oysters and its implications for aquaculture. Can. J. Genet. Cytol., 23, 119-130.

SMOUSE, P. E. 1986. The fitness consequences of multiple-locus heterozygosity under the multiplicative overdominance and inbreeding depression models. Evolution, 40, 946-957.

SOKAL, R. R. AND ROHLF, F. J. 1981. Biometry. Freeman and Company, San Francisco.

STRAUSS, S. H. 1986. Heterosis at allozyme loci under inbreeding and crossbreeding in Pinus attenuata. Genetics, 113, $115-134$.

WALNE, P. R. 1964. Observations on the fertility of the oysters (Ostrea edulis). J. Mar. Biol. Ass. U.K., 44 293-310.

WILKINS, N. P. AND MATHERS, N. F. 1973. Enzyme polymorphism in the European oyster, Ostrea edulis L. Anim. Blood. Grps. Biochem. Genet., 4, 41-47.
WORKMAN, P. L. 1969. The analysis of simple genetic polymorphisms. Hum. Biol., 412, 97-114.

ZOUROS, E. AND FOLTZ, D. W. 1984a. Minimal selection requirements for the correlation between heterozygosity and growth, and for the deficiency of heterozygotes, in oyster populations. Dev. Genet., 4, 393-405.

ZOUROS, E. AND FOLTZ, D. W. $1984 \mathrm{~b}$. Possible explanations of heterozygote deficiency in bivalve molluscs. Malacologia, 25, 583-591.

ZOUROS, E. AND FOLTZ, D. W. 1987. The use of allelic isozyme variation for the study of heterosis. In Rattazzi, M. C., Scandalios, J. G. and Whitt, G. S. (eds) Isozymes: Current Topics in Biological and Medical Research, vol. 13, A. R. Liss, New York, pp. 1-59.

ZOUROS, E., ROMERO-DOREY, M. AND MALLET, A. L. 1988. Heterozygosity and growth in marine bivalves: further data and possible explanations. Evolution, 42, 1332-1341.

ZOUROS, E., SINGH, S. M., FOLTZ, D. W. AND MALLET, A. L. 1983. Post-settlement viability in the American oyster (Crassostrea virginica): an overdominant phenotype. Genet. Res., 41, 259-270.

ZOUROS, E., SINGH, S. M. AND MILES, H. E. 1980. Growth rate in oysters: an overdominant phenotype and its possible explanations. Evolution, 34, 856-867. 